\title{
The association between altered lipid profile and suicide attempt among Tunisian patients with schizophrenia
}

\author{
Rym Mensi ${ }^{1,3^{*}} \mathbb{0}$, Amal Messaoud ${ }^{1,3}$, Ahmed Mhallah ${ }^{1,2}$, Islem Azizi ${ }^{1,3}$, Walid Haj Salah ${ }^{1,2}$, Wahiba Douki ${ }^{1,3}$, \\ Mohamed Fadhel Najjar ${ }^{3}$ and Lotfi Gaha ${ }^{1,2}$
}

\begin{abstract}
Background: There have been many studies on psychiatric disorders, but very little is known about the biology of suicide with schizophrenia. In the present study, we are looking for a possible connection between altered lipid profile and suicidal behavior in schizophrenic Tunisian patients.

Methods: Assay of total cholesterol (TC), high-density lipoprotein cholesterol (HDL-C), low-density lipoprotein cholesterol (LDL-C), and triglycerides (TG) has been done for 126 schizophrenic patients with and without suicide attempts and 131 healthy controls recruited in the University Hospital of Monastir.

Results: TC and LDL-c levels were significantly higher in schizophrenic patients compared to controls. TC was significantly lower in schizophrenic patients with suicide attempt compared to those without suicide attempt. Depending to the sonority of suicide attempt, TC was significantly lower in patients with recent suicide attempt compared to those with lifetime suicide attempt and without suicide attempt $(p<0.001)$, and no significant differences between $\mathrm{TG}, \mathrm{LDL}-\mathrm{C}$, and HDL-c were noted.

Conclusions: Results of this study showed that TC levels in schizophrenic patients after a recent suicide attempt are significantly lower than in patients without suicide attempt and with lifetime suicide attempts. TC can be one of biological markers defined suicidal risk for schizophrenic patients.
\end{abstract}

Keywords: Lipids, Cholesterol, Schizophrenia, Suicide

\section{Background}

Suicide, a public health problem of high complexity with different etiological factors, is causing annually a premature loss of approximately one million lives worldwide [4] Suicide is the third most common cause of death in various countries in the 15-44 years age group, and the second most common cause of death in the 10-24 years age group (OMS [28]), and is still poorly understood. New approaches are therefore needed to complement the fundamental of social influences, cultural and individual propensity to suicide. Suicide is the chief cause of premature

\footnotetext{
*Correspondence: rim.mensi@gmail.com

1 Research Laboratory "Vulnerability to Psychotic Disorders LR05ES10",

Faculty of Medicine, University of Monastir, 5012 Monastir, Tunisia

Full list of author information is available at the end of the article
}

death among patients with schizophrenia [5]. The rate of suicide in schizophrenic patients is several times higher than in the general population. Identification of those at highest risk remains a problem for the clinician. Patients who have previously attempted suicide form a welldefined, high-risk group for suicide. It has been shown in other studies $[16,17,39]$ that the prevalence of lifetime suicide attempts in females is almost twice than of males ( 7 vs. $4 \%$, respectively), although the difference did not reach significant level.

In particular, improved prevention strategies are required in addition to extensive scientific study. Many researchers have focused on the search of biological markers that may be linked to suicidal behavior and can be used as an additional instrument for prevention and therapeutic action. It has been found that metabolic 
deregulation, especially altered lipid profile including low total cholesterol (TC) and low-density lipoproteins-cholesterol (LDL-c) levels, may underlie higher suicide risk in patients with schizophrenia [1,3]. A number of studies have investigated a possible link between low serum cholesterol and psychiatric symptoms, especially suicidal behavior [36]. These findings might be explained by the hypothesis that reduced cholesterol level contributes to decreased serotonergic transmission due to altered affinity and function of serotonin receptors and transporters [8]. It has been further hypothesized that low peripheral and central cholesterol levels may reduce lipid viscosity of neuronal cell membranes lowering the availability of pre-synaptic serotonin transporters and post-synaptic serotonin receptors $[21,38]$. However, it should also be noted that some studies have failed to prove an association between lipid profile and suicide in patients with schizophrenia [20, 22, 29, 34]. In sum, cholesterol has received attention as a potentially meaningful biomarker for suicide.

Most previous studies with clinical population had small samples, and focused on total cholesterol as the measure of interest. Given that each lipoprotein subfraction has a different role in the human body, total cholesterol might not be sufficient to determine the relationship between lipids and suicidality. Additionally, it is not clear whether a lower lipid profile is either a state or trait marker for suicide. Other blood markers should be compared in the same population to investigate potential biomarkers equally and to evaluate group differences between suicide attempters and non-attempters.

Therefore, in the present study, we investigated the possible connection between serum cholesterol, triglycerides, HDL-c and LDL-c levels, and suicide for schizophrenic patients with and without suicide attempts and healthy controls.

\section{Methods}

\section{Patients}

The protocol of this study was approved by the ethical committees of the University Hospital in Monastir. After providing consent, 126 subjects (91 men and 35 women) with the age range of 20-65 years were recruited during 11 months (April 2013-March 2014) at the Department of psychiatry, in the University Hospital of Monastir, which is located in the Mid-eastern part of Tunisia. We recruited patients randomly but only those that met the inclusion criteria for our study. Socio-demographic and clinical data were collected by an information sheet and from the medical record of the patient. We excluded all patients with metabolic disorders. The blood sample of the control group was taken from the blood bank of University Hospital in Monastir Tunisia; 131 Healthy controls (94 men and 37 women) did not have any mental or metabolic illness and they are in the same age range of patients (20-65 years). The suicide attempts were divided into two groups: lifetime suicide group (who had attempted suicide for more than 2 months) and recent suicide group (who had attempted suicide for less than 2 months). BMI was calculated as the weight (kilograms) divided by the square of the height (square meters).

\section{Assessment}

Venipuncture was performed for all subjects between 8 and 9 a.m. after a $12 \mathrm{~h}$ overnight fast. Approximately $5 \mathrm{ml}$ of blood was collected. Immediately after collecting blood samples, serum concentration of total cholesterol (TC), high-density lipoprotein cholesterol (HDL-c), and triglycerides (TG) were determined using enzyme methods on COBAS $6000^{\mathrm{TM}}$ automates analyzer, and low-density lipoprotein cholesterol (LDL-c) was calculated with the Friedewald equation. Reference intervals for the measured parameters were as follows: $\mathrm{TC}<5.0 \mathrm{mmol} / \mathrm{L}, \mathrm{LDL}<3.0 \mathrm{mmol} / \mathrm{L}, \mathrm{HDL}>1.0 \mathrm{mmol} / \mathrm{L}$, and TG $<1.7 \mathrm{mmol} / \mathrm{L}$.

\section{Measurements}

Table 1 shows comparison of socio-demographic details (age, gender, BMI, smoking status, and alcoholic status) between patients and controls.

The structured clinical interview for diagnostic and statistical manual of mental disorder-IV (DSM-IV) for schizophrenia was applied to assess the psychiatric status of individuals.

In the current study, we have two groups: schizophrenic patients and healthy controls. Schizophrenic patients are divided into schizophrenic patients without suicide attempts, schizophrenic patients with lifetime suicide attempts, and schizophrenic patients with recent suicide attempts.

\section{Psychometric scales}

For all patients, we conducted a psychometric assessment through psychometric scales: PANSS (Positive and Negative Syndrome Scale) which enables the assessment of positive symptoms, negative, and general psychopathology, CGI (Clinical Global Impression) which allows assessment of the severity, the therapeutic index, and improvise patients under treatment, EGF (Global Assessment of Function), BPRS (Brief Psychiatric Rating Scale), and CALGAGY (Depression Scale For Schizophrenia).

\section{Data analysis methods}

Data collected from medical, laboratory, and treatment records were noted and entered into a database: SPSS for the Windows 20.0 package program was used for analyses 
Table 1 Demographic characteristics of different groups of study population

\begin{tabular}{|c|c|c|c|}
\hline \multirow{2}{*}{$\begin{array}{l}\text { Demographic } \\
\text { characteristics }\end{array}$} & \multicolumn{2}{|l|}{ $\pm S D /$ freq. (\%) } & \multirow[t]{2}{*}{$p$} \\
\hline & Schizophrenia group $(n=126)$ & Controls group $(n=131)$ & \\
\hline \multicolumn{4}{|l|}{ Gender } \\
\hline Male & 91 (72.2\%) & 94 (71.8\%) & \multirow[t]{2}{*}{0.934} \\
\hline Female & 35 (27.8\%) & 37 (28.2\%) & \\
\hline Sex ratio & 2.6 & 2.54 & \\
\hline Age (year) & $43.44 \pm 10.60$ & $40.81 \pm 14.60$ & 0.101 \\
\hline BMI $\left(\mathrm{kg} / \mathrm{m}^{2}\right)$ & $26.25 \pm 5.86$ & $24.86 \pm 3.82$ & 0.026 \\
\hline \multicolumn{4}{|l|}{ Smoking status } \\
\hline Smoking & 73 (57.9\%) & $54(41.2 \%)$ & \multirow[t]{3}{*}{0.713} \\
\hline No-smoking & 51 (40.5\%) & 77 (58.8\%) & \\
\hline Weaned & $2(1.6 \%)$ & $0(0 \%)$ & \\
\hline \multicolumn{4}{|l|}{ Alcoholic status } \\
\hline Consumer & $24(19 \%)$ & $14(10.7 \%)$ & \multirow[t]{2}{*}{0.056} \\
\hline No-consumer & 102 (81\%) & $117(89.3 \%)$ & \\
\hline
\end{tabular}

to compare the clinical and demographic characteristics variables between patients and healthy subjects.

All data are presented as the mean \pm standard deviation (SD) or as n (\%). Analysis of various, Chi square test, independent simple $t$ test, was used for the comparisons whenever appropriate. A result of $p<0.05$ was accepted as significant.

\section{Results and discussion}

A total of 126 subjects with schizophrenic disorders were included in this study; 55 subjects had presented an episode of suicide attempt ( 15 had a recent suicide attempters and 40 had a lifetime suicide attempters) and 71 patients without any suicidal behavior. In this study, we have more males than females (Table 1).

BMI was significantly higher in schizophrenic patients compared to controls. The majorities of our patients smoke and do not consume alcohol.

Suicidal thoughts were reported by $37.4 \%$ of men and $60 \%$ of women with schizophrenia. The predominant type of schizophrenia was undifferentiated for patients without suicide attempt $(47.88 \%)$ and paranoid for patients with suicide attempt (45.44\%).The majority of the prescribed Antipsychotic Drugs are typical (83.1\%). In this study, we found that differences in psychometric scores between patients with and without suicide attempt are significantly higher in schizophrenic patients with suicide attempts for PANSS (general, positive, and negative), CGI Severity and BPRS are significantly higher in schizophrenic patients with suicide attempts (Table 2).

Concentrations of total cholesterol and LDL-c were significantly higher in schizophrenic patients compared with controls. No relationship with HDL-c and triglycerides was found (Fig. 1).

Each lipid measure of the schizophrenic patients with recent suicide attempt, with lifetime suicide attempts, and without suicide attempt is shown in Table 3 . The level of TC in the schizophrenic group with recent suicide attempts was significantly lower than schizophrenic groups with lifetime suicide attempts and without suicide attempts. There were no statistically significant differences in the LDL-c, HDL-c, and TG levels between these groups.

The comparison reveals no differences in concentrations of TC, TG, HDL-c, and LDL-c between patients treated with typical, atypical, and association between these two classes of Neuroleptics drug (Table 4).

Significant correlations between TC levels and EGF score as well as between the differences in TC levels and CALGARY score were found only for the subgroup of recent suicide attempters, indicating that TC levels may serve as a predictive factor for suicide attempts in patients with schizophrenia. There were also no associations between TC levels and score in PANSS (general, positive, and negative), CGI (severity, over all improvement, and therapeutic index), and BPRS (Table 5).

According to the threshold values represented by the Roc curve (Figs. 2 and 3), we divided our study of population to compare the effective of each interval. The results are summarized in Table 6.

In suicidal risk for patients with schizophrenia, the cutoff value of $3.76 \mathrm{mmol} / \mathrm{L}$ of TC was optimum, and at that point, sensitivity was $69 \%$ and specificity $31 \%$. The area 
Table 2 Clinical characteristics of schizophrenic patients with and without suicide attempts

\begin{tabular}{|c|c|c|c|}
\hline & Patients without SA $(n=71)$ & Patients with SA $(n=55)$ & $p$ \\
\hline \multicolumn{4}{|l|}{ Psychometric evaluation } \\
\hline PANSS general & $35.25 \pm 14.97$ & $41.71 \pm 15.86$ & 0.021 \\
\hline PANSS positive & $14.70 \pm 6.83$ & $19.80 \pm 8.88$ & $<0.001$ \\
\hline PANSS negative & $17.52 \pm 8.93$ & $20.76 \pm 9.02$ & 0.046 \\
\hline CGI severity & $3.01 \pm 1.61$ & $3.31 \pm 1.46$ & $<0.001$ \\
\hline CGl overall improvement & $2.32 \pm 1.20$ & $2.22 \pm 0.91$ & 0.292 \\
\hline CGI therapeutic index & $4.94 \pm 3.49$ & $5.20 \pm 3.34$ & 0.590 \\
\hline EGF & $61.42 \pm 18.21$ & $53.27 \pm 17.44$ & 0.678 \\
\hline BPRS & $53.49 \pm 23.53$ & $69.24 \pm 25.24$ & 0.012 \\
\hline Calgary & $6.56 \pm 10.11$ & $8.31 \pm 6.21$ & 0.262 \\
\hline \multicolumn{4}{|l|}{ Type of schizophrenia } \\
\hline Undifferentiated & $35(47.88 \%)$ & $17(30.90 \%)$ & 0.113 \\
\hline Paranoid & $23(32.39 \%)$ & $25(45.44 \%)$ & \\
\hline Disorganized & $13(18.30 \%)$ & $13(23.64 \%)$ & \\
\hline \multicolumn{4}{|l|}{ Neuroleptics } \\
\hline Typical & $59(83.1 \%)$ & $47(85.5 \%)$ & 0.952 \\
\hline Typical and atypical & $12(16.9 \%)$ & $8(13.5 \%)$ & \\
\hline Doses of chlorpromazine & $990.07 \pm 617.703$ & $963.18 \pm 652.663$ & 0.814 \\
\hline Age at onset (year) & $25.99 \pm 8.39$ & $25.26 \pm 8.98$ & 0.643 \\
\hline
\end{tabular}

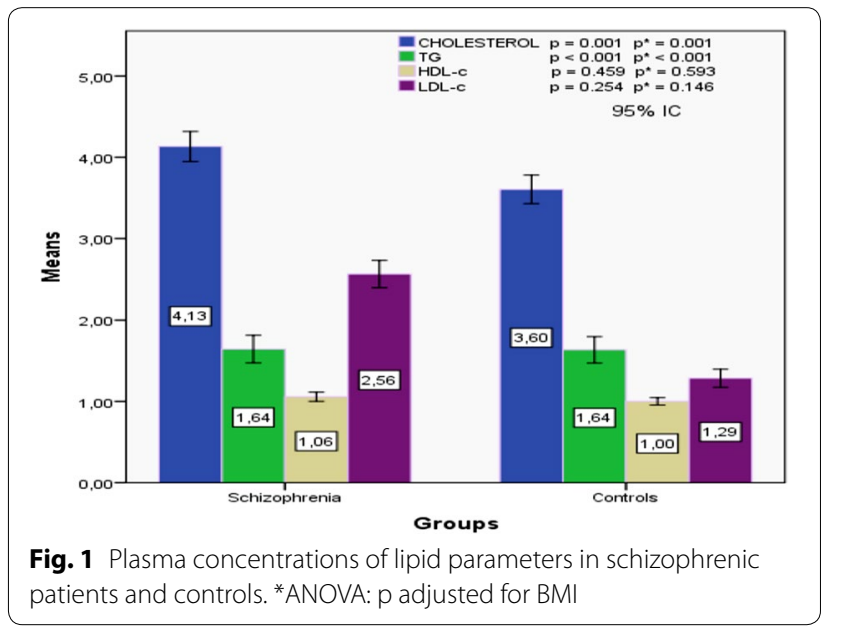

under the curve was statistically significantly lower in patients with a recent suicide attempt than for patients without suicide attempt $(p<0.001)$.
Schizophrenia is a serious mental disorder, and previous literature has reported that suicide was one of the main causes of premature death for sufferers from schizophrenia which was the major risk factor for complete suicide [32]. Cholesterol is a core component of the central nervous system (CNS), essential for the cell membrane stability, and the correct functioning of neurotransmission [33]. In our study, we found that TC was significantly higher among patients with schizophrenia compared to controls. Other studies have also shown that TC is higher among patients with schizophrenia compared to controls [25].

Considering the type of schizophrenia and according to our results and considering the type of schizophrenia, the majority of our patients with a suicide attempts are paranoid-type $(41.81 \%)$, while the majority of patients without a suicide attempts are undifferentiated $(46,47 \%)$, but the difference between the two types was not significant. The same results were found by Huang et al. [22].

Table 3 Comparison of lipid profile in schizophrenic patients depending on the seniority of suicide attempt

\begin{tabular}{|c|c|c|c|c|c|c|c|}
\hline Blood levels & $\begin{array}{l}\text { Recent suicide } \\
\text { attempters } \\
\text { Group } 1(n=15)\end{array}$ & $\begin{array}{l}\text { Lifetime suicide } \\
\text { attempters } \\
\text { Group } 2(n=40)\end{array}$ & $\begin{array}{l}\text { Never-suicide } \\
\text { attempters } \\
\text { Group } 3(n=71)\end{array}$ & $p$ & $\begin{array}{l}{[1] \text { vs. [3] }} \\
p\end{array}$ & $\begin{array}{l}{[1] \text { vs. [4] }} \\
p\end{array}$ & $\begin{array}{l}{[3] \text { vs. [4] }} \\
p\end{array}$ \\
\hline $\mathrm{TC}(\mathrm{mmol} / \mathrm{L})$ & $3.19 \pm 1.00$ & $4.02 \pm 0.96$ & $4.39 \pm 0.98$ & 0.000 & 0.007 & 0.000 & 0.063 \\
\hline $\mathrm{HDL}-\mathrm{C}(\mathrm{mmol} / \mathrm{L})$ & $1.66 \pm 0.94$ & $1.64 \pm 1.04$ & $1.64 \pm 0.93$ & 0.995 & 0.935 & 0.920 & 0.994 \\
\hline LDL-C (mmol/L) & $1.04 \pm 0.36$ & $1.04 \pm 0.27$ & $1.04 \pm 0.27$ & 0.921 & 0.947 & 0.848 & 0.691 \\
\hline TG (mmol/L) & $2.60 \pm 0.50$ & $2.62 \pm 1.11$ & $2.62 \pm 1.12$ & 0.847 & 0.934 & 0.746 & 0.597 \\
\hline
\end{tabular}


Table 4 Variations of lipid profile in schizophrenic patients according to the treatment

\begin{tabular}{lllll}
\hline & \multicolumn{2}{l}{ Neuroleptics } & $p$ & $p$ \\
\cline { 2 - 4 } & Typical [1] & Atypical [3] & $\begin{array}{l}\text { Typical and atypi- } \\
\text { cal [4] }\end{array}$ & \\
\hline $\mathrm{TC}(\mathrm{mmol} / \mathrm{L})$ & $4.16 \pm 1.07$ & $4.05 \pm 0.25$ & $4.05 \pm 1.01$ & 0.933 \\
$\mathrm{TG}(\mathrm{mmol} / \mathrm{L})$ & $1.70 \pm 1.41$ & $1.41 \pm 0.87$ & $1.26 \pm 0.64$ & 0.210 \\
$\mathrm{HDL}-\mathrm{C}(\mathrm{mmol} / \mathrm{L})$ & $1.03 \pm 0.28$ & $1.21 \pm 0.36$ & $1.17 \pm 0.48$ & 0.145 \\
$\mathrm{LDL}-\mathrm{C}(\mathrm{mmol} / \mathrm{L})$ & $2.57 \pm 0.98$ & $2.25 \pm 0.50$ & $2.56 \pm 0.72$ & 0.797 \\
\hline
\end{tabular}

Table 5 Correlation of lipid profile in schizophrenic patients according to the psychometric evaluation for patients with recent suicide attempt

\begin{tabular}{|c|c|c|c|c|}
\hline & $\mathrm{TC}(\mathrm{mmol} / \mathrm{L})$ & $\mathrm{TG}(\mathrm{mmol} / \mathrm{L})$ & $\mathrm{HDL}-\mathrm{c}(\mathrm{mmol} / \mathrm{L})$ & LDL-c ( $\mathrm{mmol} / \mathrm{L})$ \\
\hline \multicolumn{5}{|c|}{ PANSS general } \\
\hline$r$ & -0.050 & -0.19 & -1.17 & 0.04 \\
\hline$p$ & 0.575 & 0.830 & 0.191 & 0.967 \\
\hline \multicolumn{5}{|c|}{ PANSS +} \\
\hline$r$ & -0.11 & -0.014 & -0.093 & 0.076 \\
\hline$p$ & 0.901 & 0.875 & 0.301 & 0.398 \\
\hline \multicolumn{5}{|c|}{ PANSS - } \\
\hline$r$ & 0.073 & 0.018 & -0.020 & -0.006 \\
\hline$p$ & 0.418 & 0.844 & 0.824 & 0.946 \\
\hline \multicolumn{5}{|c|}{ CGI severity } \\
\hline r & -0.036 & 0.029 & -0.142 & 0.039 \\
\hline$p$ & 0.689 & 0.749 & 0.114 & 0.664 \\
\hline \multicolumn{5}{|c|}{ CGI improving patients under treatment } \\
\hline$r$ & -1.06 & 0.051 & -0.075 & -0.006 \\
\hline$p$ & 0.237 & 0.569 & 0.404 & 0.945 \\
\hline \multicolumn{5}{|c|}{ CGI therapeutic index } \\
\hline$r$ & -0.057 & -0.075 & -0.090 & -0.06 \\
\hline$p$ & 0.523 & 0.406 & 0.315 & 0.502 \\
\hline \multicolumn{5}{|c|}{ EGF } \\
\hline$r$ & -0.186 & -0.058 & -0.0514 & -0.119 \\
\hline$p$ & 0.037 & 0.515 & 0.550 & 0.184 \\
\hline \multicolumn{5}{|c|}{ Calgary } \\
\hline$r$ & 0.222 & -0.046 & 0.132 & 0.150 \\
\hline$p$ & 0.012 & 0.609 & 0.139 & 0.093 \\
\hline
\end{tabular}

The gender difference regarding risk of suicide attempt is well known. The well-known risk of attempted suicide is higher in females [31]. Accordingly, our study included more males than females with a suicide attempt. Higher frequency of alcohol consumption is found for patients (19\%) compared to healthy controls (10.7\%). In this study, alcohol consumption is less frequent compared to the results of North America or European studies which found high rates of use alcohol (rang 21-51\%) [12]. These differences may be linked to availability of alcohol or cultural factors, in particular to the social pressure for alcohol abstinence in Tunisia as in other Islamic countries (Table 7).

Therefore, the results obtained here corroborate most studies in which a relationship between suicidal behavior and low TC in schizophrenia patients was observed $[26,27]$. Other studies did not find associations between serum cholesterol and death by suicide in patients with schizophrenia [35]. Some studies about attempted suicide mainly focused on patients suffering from major depression. Almeida-Montes et al. [2] found no significant difference in lipid profiles between patients who had attempted suicide and those who had not among patients with a diagnosis of a major depressive episode. No association between TC levels and suicidal act was shown in bipolar patients and those with major depressive disorder [8]. The same study showed that TG is significantly lower in those patients. The question has thus arisen as to why cholesterol levels have been found to be correlated with suicide attempts in some studies and not in others. Race differences in serum lipid profiles and lipoprotein lipase activity may be a culprit [15]; nutritional habits, life style, traditions, as well as seasons and climate may play a role in explaining these differences $[10,18,19]$.

On the other hand, no association with Triglycerides, LDL cholesterol, and HDL cholesterol was observed in these patients for any lipidic parameter, which was also the case in the present study. However, Janusz et al. [23] have reported that total cholesterol, LDL cholesterol, total lipids, and triglycerides are significantly lower in patients with schizophrenia who had a suicidal attempt. In terms of gender differences, we must emphasize that females may be especially sensitive to dieting-induced changes in the central serotonin function [39].

Lower lipid levels in people with schizophrenia may also relate to the occurrence of metabolic syndrome. In relation to this, Vuksan-Cusa et al. [37] observed that the prevalence of metabolic syndrome in people with schizophrenia was lower in suicide attempters than in non-attempters. A post-mortem study reported down regulation of lipid metabolism mortem genes in the frontal cortex of suicide completers [24].

The aims of our study was to calculate the new cutoff value of total cholesterol according to the location of suicide in schizophrenic patients using Roc curve which was described by plotting the sensitivity on the $y$-axis against 1-specificity on the $\mathrm{x}$-axis for each of several cutoffs. The results are interesting for total cholesterol in which $80 \%$ of patients with recent suicide attempt have a rate of $\mathrm{TC} \leq 3.76$ against $36.6 \%$ for patients without suicide attempt. Among patients who have not attempted suicide, $36.6 \%$ had rate of total cholesterol $\leq 3.76$. Lipid profile of these patients should be controlled regularly to prevent suicide risk among them. 


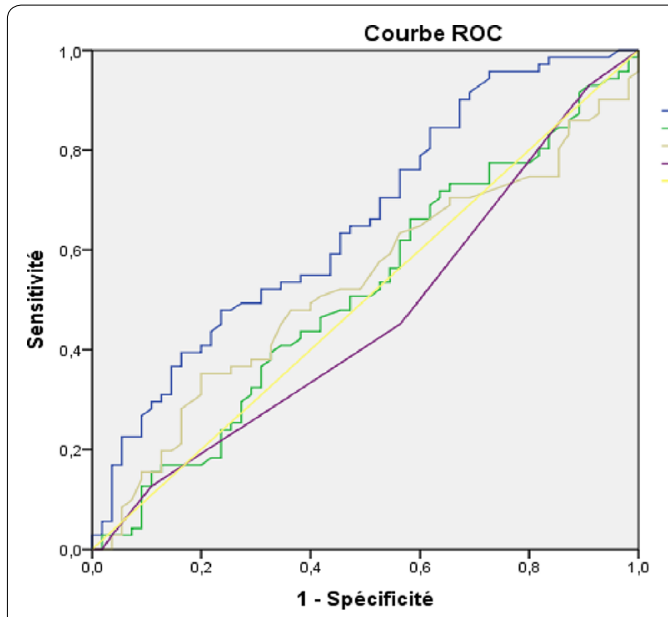

$$
\begin{gathered}
\text { Source de la } \\
\text { courbe } \\
\text { - CHOLESTEROL } \\
\text { TG } \\
\text { HDLC }
\end{gathered}
$$

Ligne de rétérence

\begin{tabular}{|l|l|l|l|l|}
\hline AUC & Sensibility & Specificity & Cut off value & p \\
\hline
\end{tabular}

Les segments diagonaux sont générés par des liaisons.

\begin{tabular}{|c|c|c|c|c|c|}
\hline CL $(\mathrm{mmol} / \mathrm{L})$ & 0.658 & $56.3 \%$ & $43.7 \%$ & 3.76 & $\mathbf{0 . 0 0 2}$ \\
\hline HDL-C $(\mathrm{mmol} / \mathrm{L})$ & 0.463 & $45.1 \%$ & $54.9 \%$ & 1.58 & 0.563 \\
\hline LDL-C (mmol/L) & 0.530 & $45.1 \%$ & $54.9 \%$ & 1.05 & 0.480 \\
\hline TG $(\mathrm{mmol} / \mathrm{L})$ & 0.514 & $42.3 \%$ & $57.7 \%$ & 1.99 & 0.785 \\
& & & & & \\
\hline
\end{tabular}

Fig. 2 Roc curve assessing the different threshold values (TC, TG, HDL-C, and LDL-c) for patients with schizophrenia based on SA history

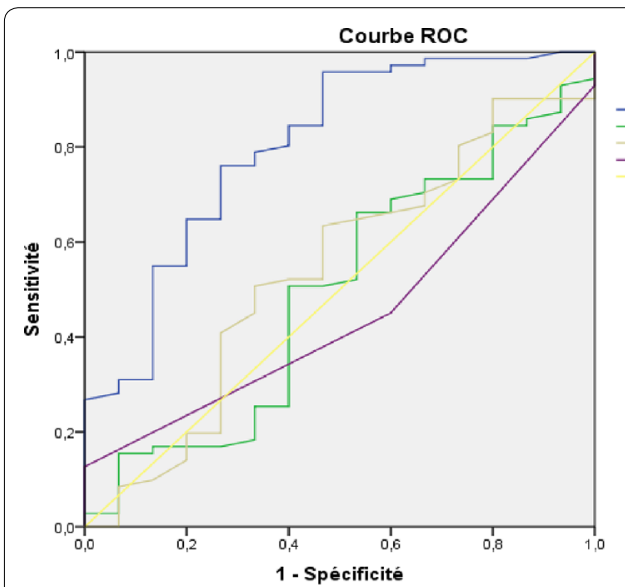

$$
\begin{aligned}
& \text { Source de la } \\
& \text { courbe } \\
& \text { - CHOLESTEROL } \\
& \text { - TG } \\
& \text { HDLC } \\
& \text { - LLLC } \\
& \text { Ligne de référence }
\end{aligned}
$$

\begin{tabular}{|c|c|c|c|c|c|}
\hline & \multicolumn{2}{|l|}{ Schizophrenia } & \multirow[t]{2}{*}{ OR } & \multirow[t]{2}{*}{ Confidence interval 95\% } & \multirow[t]{2}{*}{$p$} \\
\hline & Without SA $N=71$ & With SA $N=55$ & & & \\
\hline \multicolumn{6}{|c|}{$\mathrm{TC}(\mathrm{mmol} / \mathrm{L})$} \\
\hline$\leq 3.51$ & $12(16.9 \%)$ & $21(38.2 \%)$ & 3.037 & $1.330-6.932$ & 0.002 \\
\hline$>3.51$ & $59(83.1 \%)$ & $34(61.8 \%)$ & & & \\
\hline \multicolumn{6}{|c|}{$\mathrm{TG}(\mathrm{mmol} / \mathrm{L})$} \\
\hline$\leq 1.61$ & $41(57.7 \%)$ & $34(61.8 \%)$ & 0.844 & $0.411-1.733$ & 0.785 \\
\hline$>1.61$ & $30(42.3 \%)$ & $21(38.2 \%)$ & & & \\
\hline \multicolumn{6}{|c|}{$\mathrm{HDL}-\mathrm{C}(\mathrm{mmol} / \mathrm{L})$} \\
\hline$\leq 1.10$ & $39(54.9 \%)$ & $36(65.5 \%)$ & 0.643 & $0.311-1.330$ & 0.563 \\
\hline$>1.10$ & $32(45.1 \%)$ & $19(34.5 \%)$ & & & \\
\hline \multicolumn{6}{|c|}{$\mathrm{LDL}-\mathrm{C}(\mathrm{mmol} / \mathrm{L})$} \\
\hline$\leq 2.5$ & $39(54.9 \%)$ & $24(43.6 \%)$ & 1.574 & $0.775-3.198$ & 0.480 \\
\hline$>2.5$ & $32(45.1 \%)$ & $31(56.4 \%)$ & & & \\
\hline
\end{tabular}

\begin{tabular}{|c|c|c|c|c|c|}
\hline TC $(\mathrm{mmol} / \mathrm{L})$ & 0.801 & $69 \%$ & $31 \%$ & 3.76 & $<\mathbf{0 . 0 0 1}$ \\
\hline HDL-C $(\mathrm{mmol} / \mathrm{L})$ & 0.496 & $33.8 \%$ & $66.2 \%$ & 1.71 & 0.964 \\
\hline LDL-C $(\mathrm{mmol} / \mathrm{L})$ & 0.598 & $38 \%$ & $62 \%$ & 1.13 & 0.641 \\
\hline TG $(\mathrm{mmol} / \mathrm{L})$ & 0.449 & $45.1 \%$ & $54.9 \%$ & 2.5 & 0.539 \\
\hline
\end{tabular}

Les segments diagonaux sont générés par des liaisons.

Fig. 3 Roc curve assessing the different threshold values (TC, TG, HDL-C, and LDL-c) for patients with schizophrenia based on seniority of SA history

Table 6 Total cholesterol, triglycerides, HDL-C, and LDL-c levels in schizophrenic patients with and without suicide attempters 
Table 7 Total cholesterol, triglycerides, HDL-C, and LDL-c levels in schizophrenic patients with schizophrenia based on seniority of SA

\begin{tabular}{|c|c|c|c|c|c|}
\hline & \multicolumn{2}{|c|}{ Schizophrenia } & \multirow[t]{2}{*}{ OR } & \multirow{2}{*}{$\begin{array}{l}\text { Confidence } \\
\text { interval } 95 \%\end{array}$} & \multirow[t]{2}{*}{$p$} \\
\hline & Lifetime SA & Recent SA & & & \\
\hline \multicolumn{6}{|c|}{$\mathrm{TC}(\mathrm{mmol} / \mathrm{L})$} \\
\hline$\leq 3.76$ & $26(36.6 \%)$ & $12(80 \%)$ & 6.923 & $1.787-26.816$ & $<0.001$ \\
\hline$>3.76$ & 45 (63.4\%) & $3(20 \%)$ & & & \\
\hline \multicolumn{6}{|c|}{ TG (mmol/L) } \\
\hline$\leq 1.71$ & $46(64.8 \%)$ & $9(60 \%)$ & 1.227 & $0.392-3.843$ & 0.964 \\
\hline$>1.71$ & 25 (35.2\%) & $6(40 \%)$ & & & \\
\hline \multicolumn{6}{|c|}{ HDL-c (mmol/L) } \\
\hline$\leq 1.13$ & $44(62 \%)$ & $11(73.3 \%)$ & 0.593 & $0.171-2.049$ & 0.641 \\
\hline$>1.13$ & 27 (38\%) & $4(26.7 \%)$ & & & \\
\hline \multicolumn{6}{|c|}{ LDL-c (mmol/L) } \\
\hline$\leq 2.50$ & 39 (54.9\%) & $6(40 \%)$ & 1.828 & $0.588-5.681$ & 0.539 \\
\hline$>2.50$ & $32(45.1 \%)$ & $9(60 \%)$ & & & \\
\hline
\end{tabular}

However, a unique measure of TC level may not reflect patient's basic state. We cannot conclude if lower cholesterol is a state or a trait factor in suicide attempters. It is important to define an a priori biological threshold to distinguish subjects with low and high cholesterol. Additionally, since the study was conducted in a single university hospital, the finding may not be representative of all Tunisian patients with schizophrenia.

The absence of difference for triglyceride levels suggests that the association between cholesterol and suicidal risk is not influenced by nutritional status.

The effect of medication on cholesterol level is a potential confounder not taken into account in this study. Moreover, psychotropic drugs are usually associated with high cholesterol levels.

The relationship between low serum cholesterol levels and suicidal behavior is far from clear. There have been numerous hypotheses that have attempted to explain the mechanisms by which cholesterol levels may influence the risk of attempting suicide. The most widely held view is that there may be a link between serum cholesterol levels and the central nervous serotonergic system [7] via the reduction of brain serotonin activity [11]. Another hypothesis is that the phospholipids metabolism is disrupted, combining a deficit of incorporation of polyunsaturated fatty acids in the membrane with an increase their destruction [8]. Others have suggested that cholesterol may affect disease state and behaviors, as it plays a role in the production of the myelin sheath, in transmembrane exchange, enzyme function, in the synthesis of steroid hormones, and neurotransmitter receptor expression [14].
However, it should be stressed that an association between low cholesterol and suicidal behavior in schizophrenia was not confirmed in a number of studies [22, 30]. Recently, Freemantle et al. [13] analyzed brain oxysterol levels, which are enzymatic oxidation products of cholesterol, in the prefrontal cortex of suicide victims. Their results show a significant increase in 24-hydroxysterol, reflecting a higher turnover of cholesterol. They suggest that this metabolic process may be responsible for a reduction in central and peripheral cholesterol in these subjects. These authors also found altered phospholipids levels connected with increased activity of cholesteryl ester hydrolase, which may impair inhibitory neurotransmission in the prefrontal cortex of subjects with violent suicides [13].

In subsequent studies, we will aim for the study of genes implicated in the transition to the suicidal act in patients with schizophrenia. We hypothesize that an array of alteration in genes responsible for lipid regulation is incremented in the suicide for schizophrenic patients.

As most of the studies yielding negative results in this respect were performed in Asian populations, it can be speculated that ethnic differences may play a role.

\section{Conclusion}

The results show that total Cholesterol levels are low in suicide attempters after a recent suicide attempt, and remain lower than normal in a later time after the event.

Suicide prevention in patients with schizophrenia remains fundamental in the same way as the reduction of positive and negative symptoms, or improving the quality of life and reducing disability caused by the disease. We should automatically track a patient with schizophrenia suicidal risk factors or situations that promote their development.

One of the most important areas of research in suicide of schizophrenic patients should be based on the identification of biomarkers that may identify those patients prone to this risk of suicidal acts which is seemed important to focus on the specific involvement of fluidity membrane, and it is desirable to complete the analysis of lipid metabolism by assaying the various fractions of blood cholesterol to determine those included in this relationship.

\section{Limitations}

The limitations of our study are the following: First, the sample size in the recent suicide attempt subgroup was small. It would be interesting to increase the sample size for this subgroup. The data for the current study were obtained from the region of Monastir. Future studies on this research topic may be conducted in larger and more 
diverse samples. Some variables, such as lipid total, were not measured in the present study, and this issue would be considered in the future investigation.

\section{Abbreviations}

HDL-c: high-density lipoprotein cholesterol; LDL-c: low-density lipoprotein cholesterol; TC: total cholesterol; TG: triglycerides; SA: suicide attempt.

\section{Authors' contributions}

RM has made patient enrollment and dosage of biochemical parameters, and data analysis by SPSS. AM helped with the analyses using SPSS. AM conducted psychometric scales. IA helped with the dosage of biochemical parameters. WHS conducted interviews with patients. WD participated in the design of the study and performed the statistical analysis. MFN oversaw the dosage of lipidic profile. LG participated in the design of the study and its coordination, and helped to draft the manuscript. All authors read and approved the final manuscript.

\section{Author details}

${ }^{1}$ Research Laboratory "Vulnerability to Psychotic Disorders LR05ES10", Faculty of Medicine, University of Monastir, 5012 Monastir, Tunisia. ${ }^{2}$ Department of Psychiatry, University Hospital in Monastir, Monastir, Tunisia. ${ }^{3}$ Clinical Biochemistry and Toxicology Laboratory, University Hospital in Monastir, Monastir, Tunisia.

\section{Acknowledgements}

Not applicable.

\section{Competing interests}

The authors declare that they have no competing interests.

\section{Availability of data and supporting materials section}

The data will not be shared.

\section{Ethics approval and consent to participate}

This study was approved by the ethical committees of the university Hospital in Monastir.

\section{Funding}

This work was supported by the Research Laboratory "Vulnerability to Psychotic disorders" University of Monastir, Tunisian Republic and by Clinical Biochemistry and Toxicology Laboratory, University Hospital in Monastir, Tunisian Republic.

Received: 26 June 2016 Accepted: 2 December 2016

Published online: 16 December 2016

\section{References}

1. Ainiyet B, Rybakowski JK. Suicidal behavior in schizophrenia may be related to low lipid levels. Med Sci Monit. 2014:20:1486-90.

2. Almeida-Montes LG, Valles-Sanchz V, Monero-Aguilar J, et al. Relation of serum cholesterol, lipid, serotonin and tryptophan levels to severity of depression and to suicide attempts. J Psychiatry Neurosci. 2000;25:371-7

3. Atmaca M, Kuloglu M, Tezcan E, Ustundag B. Serum leptin and cholesterol levels in schizophrenic patients with and without suicide attempts. Acta Psychiatr Scand. 2003;108:208-14.

4. Bertolote JM, Fleischmann A. A global perspective in the epidemiology of suicide. Suicidology. 2002;7:6-8.

5. Caldwell CB, Gottesman II. Schizophreniaa high-risk factor for suicide: clues to risk reduction. Suicide Life Threat Behav. 1992:22:479-93.

6. Caldwell CB, Gottesman II. Schizophrenics kill themselves too: a review of risk factors for suicide. Schizophr Bull. 1990;16(4):571-89.
7. Diaz-Sastre Carmen, Baca-Garcia Enrique, Perez-Rodriguez Maria M, Garcia-Resa Eloy, Ceverino Antonio, Maria Jeronimo Saiz-Ruiz, Oquendo A, de Leon Jose. Low plasma cholesterol levels in suicidal males: a gender- and body mass index-matched case-control study of suicide attempters and non attempters. Prog Neuropsychopharmacol Biol Psychiatry. 2007;31:901-5.

8. De Graca Cantarelli M, Tramontina AC, Leite MC, Goncalves CA. Potential neuro-chemical links between cholesterol and suicidal behavior. Psychiatry Res. 2014;220:745-51.

9. De Leon J, Diaz FJ. A meta-analysis of worldwide studiesdemonstrates an association between schizophrenia and tobacco smoking behaviors. Schizophr Res. 2005;76:135-57.

10. De Leon J, Mallory P, Maw L, Susce MT, Perez-Rodriguez MM, Baca-Garcia E. Lack of replication of the association of low serum cholesterol and attempted suicide in another country raises more questions. Ann Clin Psychiatry. 2011;23:163-70.

11. De Leon J, Mallory P, Maw L, Susce MT, Perez-Rodriguez MM, Baca-Garcia E. Lack of replication of the association of low serum cholesterol and attempted suicide in another country raises more questions. Ann Clin Psychiatry. 2011;23:163-70.

12. Dervaux A, Baylé FJ, Laqueille X, Bourdel MC, Le Borgne MH, Olié JP, Krebs MO. Validity of the CAGE questionnaire in schizophrenic patientswith alcohol abuse and dependence. Schizophr Res. 2006;81:151-5.

13. Freemantle E, Chen GG, Cruceanu C, et al. Analysis of oxysterols and choles-terol in prefrontal cortex of suicides. Int J Neuropsychopharmacol. 2013;16:1241-9.

14. Golomb BA, Criqui MH, White HL, Dimsdale JE. The UCSD Statin Study: a randomized controlled trial assessing the impact of statins on selected noncardiac outcomes. Control Clin Trials. 2004;25:178-202.

15. Lee HJ, Kim YK. Serum lipid levels and suicide attempts. Acta Psychiatr Scand. 2003;108:215-21.

16. Jeon HJ, Lee JY, Lee YM, Hong JP, Won SH, Cho SJ, Kim JY, Chang SM, Lee D, Lee HW, Cho MJ. Lifetime prevalence and correlates of suicidal ideation, plan, and single and multiple attempts in a Korean nationwide study. J Nerv Ment Dis. 2010;198:643-6.

17. Jeon HJ, Lee JY, Lee YM, Hong JP, Won SH, Cho SJ, Kim JY, Chang SM, Lee HW, Cho MJ. Unplanned versus planned suicide attempters, precipitants, methods, and an association with mental disorders in a Korea based community sample. J Affect Disord. 2010;127:274-80.

18. Joffe YT, Collins M, Goedecke JH. The relationship between dietary fatty acids and inflammatory genes on the obese phenotype and serum lipids. Nutrients. 2013:5:1672-705.

19. Kamezaki F, Sonoda S, Tomotsune Y, Yunaka H, Otsuji Y. Seasonal variation in serum lipid levels in Japanese workers. J Atheroscler Thromb. 2010;17:638-43.

20. Kuo CJ, Tsai SY, Lo CH, Wang YP, Chen CC. Risk factors for completed suicide in schizophrenia. J Clin Psychiatry. 2005;66:579-85.

21. Lee BH, Kim YK. Potential peripheral biological predictors of suicidal behavior in major depressive disorder. Prog Neuropsychopharmacol Biol Psychiatry. 2011;35:842-7.

22. Huang T, Wu S. Serum cholesterol levels in paranoid and non-paranoid schizophrenia associated with physical violence or suicide attempts in Taiwanese. Psychiatry Res. 2000;96:175-8.

23. Ainiyet B, Rybakowski JK. Suicidal Behavior in schizophrenia may be related to low lipid levels. Med Sci Monit. 2014;20:1486-90.

24. Lalovic A, Klempan T, Sequeira A, Luheshi G, Turecki G. Altered expression of lipid metabolism and immune response genes in the frontal cortex of suicide completers. J Affect Disord. 2010;120:24-31.

25. Mechria Mabrouk HH, Hellara I, Ben Omrane C, Neffati F, Mechri A, Douki W, Gaha L, Najjar MF. Lipid profile and cardiovascular risk in 121 schizophrenic patients. Immuno Anal Biol Spéc. 2012;27(4):159-67.

26. Marcinko D, Popović-Knapić V, Franić T, et al. Association of cholesterol and socio-demographic parameters with suicidality in the male patients with schizophrenia. Psychiatr Danub. 2008;20:390-5.

27. Modai I, Valevski A, Dror S, Weizman A. Serum cholesterol levels and suicidal tendencies in psychiatric inpatients. J Clin Psychiatry. $1994: 55: 252-4$

28. OMS (2014) http://www.who.int/mediacentre/news/releases/2014/ suicide-prevention-report/en/. Accessed 30 July 2016 
29. Park S, Yi KK, Lim A, Hong JP. No association between serum cholesterol and death by suicide in patients with schizophrenia, bipolar affective disorder, or major depressive disorder. Behav Brain Funct. 2013;9:45.

30. Park S, Yi KK, Na R, Lim A, Hong JP. No association between serum cholesterol and death by suicide in patients with schizophrenia, bipolar affective disorder, or major depressive disorder. Behav Brain Funct. 2013;9:45

31. Rihmer Z, Gonda X, Torzsa P, Kalabay L, Akiskal HS, Eory A. Affective temperament history of suicide attempt and family history of suicide in general practice patients. J Affect Disord. 2013;149:350-4

32. Saha S, Chant D, McGrath J. A systematic review of mortality in schizophrenia: is the differential mortality gap worsening over time. Arch Gen Psychiatry. 2007;64:1123-31.

33. Ghaemi SN, Shields GS, Hegarty JD, Goodwin FK. Cholesterol levels in mood disorders: high or low. Bipolar Disord. 2000;2:60-4.

34. Steinert T, Woelfle M, Gebhardt RP. No correlation of serum cholesterol levels with measures of violence in patients with schizophrenia and nonpsychotic disorders. Eur Psychiatry. 1999;14:346-8.
35. Park S, Yi KK, Na R, Lim A, Hong JP. No association between serum cholesterol and death by suicide in patients with schizophrenia, bipolar affective disorder, or major depressive disorder. Behav Brain Funct. 2013;9:45.

36. Troisi A. Cholesterol in coronary heart disease and psychiatric disorders: same or opposite effects on morbidity risk. Neurosci Biobehav Rev. 2009;33:125-32.

37. Vuksan-Cusa B, Marcinko D, Nad S, Jakovljevic M. Differences in cholesterol and metabolic syndrome between bipolar disorder men with and without suicide attempts. Prog Neuropsychopharmacol Biol Psychiatry. 2009;33:109-12.

38. Wallner $\mathrm{B}$, Machatschke $\mathrm{H}_{\mathrm{H}}$. The evolution of violence in men: the function of central cholesterol and serotonin. Prog Neuropsychopharmacol Biol Psychiatry. 2009;33:391-7.

39. Zhang J, McKeown RE, Hussey JR, Thompson SJ, Woods JR, Ainsworth BE. Low HDL cholesterol is associated with suicide attempt among young healthy women: the Third National Health and Nutrition Examination Survey. J Affect Disord. 2005;89(1-3):25-33.

\section{Submit your next manuscript to BioMed Central and we will help you at every step:}

- We accept pre-submission inquiries

- Our selector tool helps you to find the most relevant journal

- We provide round the clock customer support

- Convenient online submission

- Thorough peer review

- Inclusion in PubMed and all major indexing services

- Maximum visibility for your research

Submit your manuscript at www.biomedcentral.com/submit 